\title{
The Relationship Between Parenting Styles and Behavioral Disorders in LD Children
}

\author{
Marziyeh Azizi ${ }^{1}$, Nader Monirpour ${ }^{2}$, Sara Ebrahim Khani ${ }^{3}$ \\ ${ }^{1}$ Marziyeh Azizi, Master of Clinical Psychology, Science \& Research Tehran Branch. Islamic Azad University Saveh, \\ Iran \\ ${ }^{2}$ Nader Monirpour, Department of clinical psychology, Qom branch, Islamic Azad University, Qom, Iran \\ ${ }^{3}$ Sara Ebrahim Khani, Master of Clinical Psychology, Science \& Research Tehran Branch, Islamic Azad University \\ Saveh, Iran
}

Correspondence: Marziyeh Azizi, Marziyeh Azizi, Master of Clinical Psychology, Science \& Research Tehran Branch. Islamic Azad University Saveh, Iran.

Received: November 28, 2017 Accepted: December 6, 2017 Online Published: March 12, 2018

doi:10.5539/res.v10n2p46

URL: https://doi.org/10.5539/res.v10n2p46

\begin{abstract}
This study has been conducted with the objective of evaluating the role of parenting styles in prediction of behavioral disorders in children with Learning Disability (LD). This study is a descriptive work conducted using correlation methods in kind of prediction model and statistical population in this study consists of children with learning disability (LD) referring to Educational and Rehabilitation Centers for Specific Learning Disorders of Tehran during academic year 2014-15. Using purposeful and voluntary sampling method, 130 people were selected as sample size. Data collection instrument in this study includes Bumerind parenting style questionnaire and Child Behavior Checklist for ages 6-18 Achenbach system of empirically based assessment (CBCL). Data analysis was done using Pearson correlation and multivariate regression using SPSS. The results obtained from the study showed that there is no significant correlation between authoritarian and authoritative parenting style and any components of behavioral disorders of LD children and only permissive parenting style has negative and significant correlation with externalized disorders of LD children.
\end{abstract}

Keywords: behavioral problems of LD children, parenting styles

\section{Introduction}

Specific Learning Disorder is one of the most common disorders among children. The disorder with spread of 3-14\% in world level (American Psychiatric Association, 2013; Jacobsen et al, 2005 and Dowker, 2005) and spread of 8.18\% in Iran (Behrad, 2005) has possessed highest rate of disorders in children with specific needs (Asghari Nekah, 2012).

According to Diagnostic and Statistical Manual of Mental Disorders $5^{\text {th }}$ Edition (DSM-5), the neural-evolutional disorder with biological origin is an intangible disability causing some abnormalities in cognitive and psychological level. it can not only leave negative effects on status of children in cognitive and psychological level and not only can have significant and wide effects on status of children in sensitive ages of growth, but also it can affect performance of these children to the end of their life in different fields such as educational, social, behavioral, occupational and psychological dimensions. Comorbidity of the disorder with other disabling conditions such as behavioral disorders has been cleared over the decade (Paul and Fine, 2014; American Psychiatric Association, 2013; Freilich \& Schechtman, 2010; McNamara, 2010; Pennington, 2009; Crastnopol, 2009). 30-50\% of these children suffer from behavioral disorders in one of the 3 forms including general behavioral disorders, externalizing disorders like attention deficit hyperactivity disorder (ADHD) and internalizing disorders like anxiety (Halahan et al, 2005; quoted from Alizadeh et al, 2012; Auerbach et al, 2008; Sharma, 2004; Greman 2001, quoted from Baezzat and Rahat, 2007). The outcomes and complications of comorbid behavioral disorders with learning disorder can cause abundant preventive problems in all dimensions of personal and social life of child, family and friends and the society, where the child lives, and this can increase probability of mental and behavioral diseases in adulthood (American Psychiatric Association, 2013; Pandina et al, 2007; Miller et al, 2006). Even with presence of concerning complications of behavioral disorders, along with learning disorder encompassing all dimensions of life from childhood to adulthood, there are limited information in field of various factor affecting growth, spread and continuity of behavioral disorders of these children, especially family and parenting factors (Eslamieh, 2008). 


\section{Literature Review}

Specific learning disorder is one of the independent issues of specific education with legal position based on state and federal regulations of the US and similar regulations in other countries like Iran. In the latest definition of learning disorder presented in 2004, the disorder is defined as deficit and dysfunction in one or more basic psychological processes related to understanding and using oral or written language, which is appeared in form of disability in listening, thinking, reading, writing, spelling or mathematical calculations. It may happen along with other disabling conditions such as lack of learning opportunities, mental retardation, sensory disabilities and behavioral disorders, but it is not caused by these conditions (Halahan et al, 2005; quoted from Alizadeh et al, 2012; and National Center for Children with Learning Disabilities, 2011). One component observed in this definition and majority of definitions is the comorbidity of the disorder with other disabling conditions; meaning that LD children may suffer from one or more other disorders in addition to LD. Some of the disorders may be caused by the disorder and some of them can be cause and effective factors and some other may be caused by environmental stressful factors. Almost any kind of disorder may happen along with learning disability; although the most common disorder is behavioral disorder (Halahan et al, 2005; quoted from Alizadeh et al, 2012; Wang, 2012). According to relevant literature, more than 30-50\% of children with LD suffer from behavioral disorders (Halahan et al, 2005; quoted from Alizadeh et al, 2012; Takaloi, 2011 and Keshavarzi Valian and Keshavarzi Arshadi, 2010). Some studies have shown that learning disorders are evident in 71\% of children with ADHD and in 18-19\% of children with depression and anxiety (Greman, 2001, quoted from Baezzat and Rahat, 2007).

Achenbach has classified behavioral disorders of children in 3 groups of internalizing disorders, externalizing disorders and general disorders. Internalized disorders, also called hidden diseases, are uncompromising behavioral patterns bothering the child more than bothering people around the child. The main core of these disorders is the mood or emotion disorder and covers wide range of diagnostic system disorders based on DSM including anxiety, depression, physical complaint, active effort for isolation and avoiding social activities. The spread of these disorders in childhood is estimated in about 10-20\% of them and the behavioral problems could be evident since the age 8 (Kessler et al, 2005; Costello et al, 2003). The disorders are not transient and short-term and the continuous process of the problems can have long-term effects on behavioral activity, physical and cognitive and emotional reactions of children (Moradi and Rezaei, 2013). Externalizing disorders are behaviors directed in external aspect of child. The disorders are tangible easily from outside and are known as disruptive behaviors. In DSM-5, they can special diagnostic criteria like hyperactivity, conduct disorder, aggression, antisocial and law-breaking behavior and impulsion. The disorders are created to some extent as a result of low control or self-regulation in improper and maladaptive way. Although the two groups of disorders are apparently independent, some children may show both kind of maladaptive behaviors (Ganji, 2013) and the last group as general behavioral disorder include indices of internalizing and externalizing problems, attention deficit, thinking, social and other disorders. Both kinds of internalizing and externalizing behavioral disorders and general disorders are evident in LD children (Auerbach et al, 2008; Sideridis, 2007 and Halahan et al, 2005 quoted from Alizadeh et al, 2012). The comorbid behavioral disorders may be appeared because of problems such as stress due to educational failure, some cognitive disorders, behavior of parents against the disorder (Ganji, 2013) parenting styles and personality of parents (Sheikhi et al, 2015; Khanjani and Hodavand, 2013; Donatelli et al, 2010 and Lorber \& Egeland, 2009)

\section{Methodology}

\section{Method and Research Plan:}

This study is in kind of descriptive research conducted using correlation method in kind of prediction model.

\section{Statistical population:}

Statistical population in this study consists of parents and female and male primary school students in age range of 6-12 years old referring to Educational and Rehabilitation Centers for Specific Learning Disorders (learning disorders) in Tehran. After primary specialized examinations and evaluations, the students were diagnosed as children with learning disorders.

\section{Sample and Sampling Method}

For purpose of data collection, purposeful and voluntary sampling is used.

The desired sample consists of $130^{1}$ students educating in primary schools of cities around Tehran in age range of 6-12 years old. The students referred to Educational and Rehabilitation Centers Specific Learning Disorders of Tehran and were diagnosed as children with LD and 65 students out of them were boys and 65 students were girls.

\footnotetext{
${ }^{1}$ Statistical sample consists of 150 students with LD. After distribution and collection of questionnaires, 20 questionnaires were excluded because of insufficient reliability and 130 questionnaires were used.
} 


\section{Inclusion Criteria}

To have criteria of LD in DSM

To have average IQ

Passing the steps of diagnostic evaluation and specialized identification in centers with transient LD diagnosis

To be in age range of 6-12 years old

Living with biological mother

Presence of both parents in family

\section{Measurement Instruments}

\section{Bumerind Parenting Style Questionnaire:}

The questionnaire designed by Bumerind in 1972 contained 48 items at the first; although ultimately, 30 items were considered in final scale. The questionnaire contains 30 items. 10 items are related to permissive parenting style, 10 items are related to authoritative style and 10 items are related to authoritarian parenting style. The responding pattern of these items is based on 5-point Likert scale including totally agree, agree, almost disagree, disagree and totally disagree. In addition to responding pattern, scoring the items in Bumerind questionnaire is also based on Likert scale and through summation of relevant items of each style, 3 independent scores are obtained (Kraskian, 2013).

\section{Child Behavior Checklist for Ages 6-18 Achenbach System of Empirically Based Assessment (CBCL)}

The instrument in this study for data collection in field of internalizing and externalizing behavioral disorders is the Child Behavior Checklist (CBCL) of Achenbach System of Empirically Based Assessment (ASEBA). The age forms of the assessment system have been provided by Thomas Achenbach in 1978 and have been revised several times to so far. The assessment system includes 3 forms: Child Behavior Checklist (CBCL), Teacher Report Form (TRE) and Youth Self Report (YSR) form. In this study, the results obtained from implementing the CBCL are reported (Minaei, 2005).

Achenbach, Dimensi and Rescorla (2001) have used items with high consistency with DSM-IV diagnostic categories according to psychologists and psychiatrists and have determined some scales to point CBCL (child form), YSR (self-report) and TRF (teacher report form). DSM-based scales in 3 forms are exactly same: emotional disorders, anxiety disorders, ADHD, conduct disorders, coping behavior disorders and physical disabilities.

According to the investigations of Achenbach and Rascorla (2001) on scales based on individual experiences, they could divide the scales to 3 indices: internalizing disorders (problems, which are basically inside the person) covering 3 syndrome scales of anxiety/depression, isolation/depression and physical complaint. Second index called externalizing index (problems needing conflict with others and expectations of others from child) encompasses two scales of symptoms of law-breaking behavior and aggressive behavior. The third and last index presents general problems (including indices of internalized and externalized disorders, attention deficit, thinking and social disorders). In this study, the third index (general problems) is considered.

The checklist should be fulfilled by parents or someone who is caregiver of child and the person behaving with child in quasi-family environments and person who knows child very well based on status of child in last 6 months. In this scale, some scales are regulated based on DSM. Achenbach and Rascorla (2001) have conducted a confirmatory analysis on relevant questions of emotional-behavioral disorders of each form and called them empirically-based scales. Empirically-based scales of CBCL include anxiety/depression, isolation/depression, physical complaints, and social disorders, thinking disorders, attention disorders, law-breaking behavior and aggression.

In this form, the respondent ranks emotional, behavioral and social problems of child. Number of items contained in this checklist is 113 items and the respondents rank child's status during last 6 months in forms of false, sometimes true or absolutely or mostly true. From summation of scores of aggressive behaviors and law-breaking behaviors, the overall score of externalizing problems could be obtained (ibid).

For purpose of normalization of Achenbach empirically-based assessment in Iran, Minaei (2005) implemented the checklist using multi-stage sampling on 1438 people ( 689 girls and 749 boys) based on educational grade from 3 zones of North, Center and South of Tehran and some clients of psychiatric unit of hospital after taking required consistencies in terms of language, culture and society.

\section{Data analysis}

In this section, after data collection, sample is described using descriptive statistics including number, mean value and standard deviation (SD). 
Table 1. central statistical indices, distribution and relative distribution indices of parenting style components

\begin{tabular}{|l|l|l|l|l|l|l|}
\hline Variable & Mean & SD & Skewness & Kurtosis & Min & Max \\
\hline Permissive & 16.02 & 5.88 & 0.111 & 0.497 & 1 & 35 \\
\hline Authoritative & 17.13 & 6.75 & 0.168 & -0.384 & 0 & 34 \\
\hline Authoritarian & 31.25 & 5.41 & -1.219 & 2.550 & 11 & 40 \\
\hline
\end{tabular}

In table 1, statistical indices of parenting styles including mean value, $\mathrm{SD}$, min and max values and skewness and kurtosis are distribution of values are reported. As it is obvious, kurtosis coefficient of authoritative parenting style values shows that distribution of these values is shorter than normal distribution and kurtosis coefficient of permissive and authoritarian parenting styles shows that the distribution of these values is longer than normal distribution. Skewness coefficient of permissive and authoritative parenting style values shows that the values are right skewed and the skewness coefficient of authoritarian parenting style shows that distribution of these values is left skewed.

The results obtained from Kolmogorov-Smirnov test showed that permissive and authoritative parenting styles have normal distribution $(\mathrm{sig}=0.320$; $\mathrm{sig}=0.448)$; although authoritarian parenting style has not normal distribution $(\operatorname{sig}=0.000)$.

Table 2. central statistical indices, distribution and relative distribution of behavioral disorder components

\begin{tabular}{|l|l|l|l|l|l|l|}
\hline Variable & Mean & SD & Skewness & Kurtosis & Min & Max \\
\hline General disorders & 55.72 & 24.93 & 0.850 & 1.55 & 1 & 146 \\
\hline Internalizing disorders & 41.10 & 18.19 & 0.963 & 0.961 & 1 & 109 \\
\hline Externalizing disorders & 45 & 9.29 & 0.640 & 0.030 & 0 & 45 \\
\hline
\end{tabular}

In table 2, statistical indices of behavioral disorder components including mean value, SD and min and max value, skewness and kurtosis of distribution of values are reported. As it is observable, kurtosis coefficient of all components shows that distribution of these values is longer than normal distribution. Skewness coefficient of all components shows that distribution of these values is right skewed.

The results obtained from Kolmogorov-Smirnov test showed that general disorders have normal distribution (sig=0.057); although internalizing and externalizing disorders have not normal distribution ( $\operatorname{sig}=0.000 ; \operatorname{sig}=0.001)$.

Pearson Correlation test is used in this study and the results are presented in table 3.

Table 3. Pearson correlation between authoritarian parenting style and behavioral disorder in LD children

\begin{tabular}{|l|l|l|l|}
\hline Variables & Number & Correlation & Sig \\
\hline Authoritarian parenting style and general disorders & 130 & -0.042 & 0.319 \\
\hline Authoritarian parenting style and internalizing disorders & 130 & -0.023 & 0.399 \\
\hline Authoritarian parenting style and externalizing disorders & 130 & -0.051 & 0.283 \\
\hline
\end{tabular}

The results in table 3 show that there is no significant correlation between authoritarian parenting style and no component of behavioral disorder in LD children. Hence, hypothesis 1 is not confirmed.

\section{Conclusion}

The results obtained from the study showed that there is no significant correlation between authoritative parenting style and no one component of behavioral disorder of LD children. The result is in consistence with findings of Sheikhi et al (2015) showing that there is no significant correlation between authoritative style and behavioral disorders of children and with findings of Shiverz et al (2010) in the study on determining internalizing and externalizing behavioral disorders in early school year and showing that there is no significant correlation between authoritative parenting style and internalizing behavioral disorders in studied units. However, the result is not in consistence with findings of majority of works in literature, since the studies conducted by Hemmati and Alamdarloo (2014), Rinaldi and Howe (2012) and Lee (2010) showed positive and significant correlation between authoritative parenting style and social and behavioral 
disorders and aggression and have mentioned that this style can be significant predictor of internalizing and externalizing behavioral disorders in studied population.

Authoritative parents cause isolation and rejection of child. They have many expectations from children and show rare emotions to their children. These parents find no necessity to give a reason for their orders and give limited independence to their children and emphasize unconditional obedience and respect. Children of these parents have low independence, social skills and self-confidence. The training pattern is correlated to appearance of symptoms of depression, anxiety, antisocial behaviors, delinquency and conduct disorder (Diaz et al, 2005). The results obtained from testing the hypothesis is are in conflict with all existing discriminations and the reason could be attributed to cultural differences and different social effects out of home, especially relevant factors of school such as inadequate educational programs, inappropriate expectation in conflict with child's ability, strengthening unfavorable behavior, inconsistency in management of behavior and inappropriate patterns, which have been able to minimize effects of parenting style.

Another result obtained from this study showed that authoritarian parenting style is correlated to no component of behavioral disorder in LD children; meaning that the authoritarian parenting style can predict no component of behavioral disorders in LD children. The result is in consistence with no work in the literature. This is because; Sheikhi et al (2015) in their study on relationship between parenting styles and behavioral disorders of children showed that authoritarian parenting style is in significant and reverse statistical correlation with internalizing and externalizing problems. Also, Hemmati Alamdarloo et al (2014) found in their study that authoritarian style is negative and significant predictor of behavioral disorders such as fear, antisocial behavior and aggressiveness in children. The results obtained by Cohen et al (2009) also showed that authoritarian parenting style is negative and significant predictor of behavioral disorders in children.

In majority of relevant works of relationship between parenting styles and behavioral disorders in children, reverse correlation between authoritarian style and behavioral disorders in children is referred. Authoritarian parenting style is a logical method, in which rights of children and parents are respected; parents have reasonable expectations from children and determine transparent behavioral rules for them. At the same time that they show their kindness and intimacy to children, these parents support the constructive behaviors of children and show dissatisfaction in response to bad behaviors of child. These parents encourage their children to be independent and have open and flexible system for interactive relations with their children; consider their desires and ask about their opinions. The expectations of authoritarian parents are in consistency with ability of their children. Hence, they persuade their children that they are competent and can be successful in affairs and such behavior can cause independent behavior and increased level of self-respect in children and can protect them against behavioral disorders and children trained with such style usually take benefit of higher mental growth, social growth and educational achievement and social acceptability compared to others (Sheikhi et al, 2015; Hemmati Alamdarloo et al, 2014; Huver et al, 2010; Oliver et al, 2009).

Finally, the present study showed that among parenting styles, permissive style is significant predictor of externalizing disorders of LD children, so that the more permissive the parents behave in regard with training children, the more the probability of emergence of externalizing behavioral problems like aggressiveness and antisocial behaviors is reduced. Behavior of permissive parents is a combination of low intimacy and lack of enough control on behaviors of children. These parents have high responsiveness to their children; although they have no special expectations from them and are focused on the desires of their children and support them anywhere and under any conditions. Moreover, in field of the behavior of children, they are never challenged on behalf of their parents. It is expected that children trained under this style are mostly permissive, disobedience, overwhelming and rebellious and with least self-control ability, independence, self-regulation and responsiveness (Rinaldi and Howe, 2012).

The results of this study are in consistence with findings of no work in literature. In regard with discrimination of these findings, it seems that due to current cultural and social conditions facing increasing growth in terms of mass media, especially new information technologies such as computers, internet and various computer games and virtual and android networks; the parenting styles have been affected and the impact of thgese styles on children have been minimized and this can make children expose to lots of behavioral disorders. Moreover, in regard with explanation of the results of this study, heritance, family conditions, cultural, mental and social conditions dominated on life of children and components of school environment like teacher and friends could be referred as factors minimizing effects of parenting styles. On the other hand, comorbid behavioral disorders with LD can be caused by this disorder (LD); meaning that LD and its consequences in children can make them talented to catch behavioral disorders. This is because; repetitive failures and lack of advancement and gaining success in academic field can lead to formation of negative self-concept in children and can make them talented for social problems, depression, anxiety and so on. Moreover, these children encounter deficits and problems in field of understanding and interpreting social signs, emotions and feelings of others because of deficit in cognitive skills and basic psychological skills like executive functions, memory, attention, understanding and inference. This can cause many problems for these children in communicative, behavioral and social fields (Kafi et al, 2013). 
Biological factors (heritance) and nature of children as underlying factors in formation of personality and advent of behavioral disorders in children can be also effective in field of minimizing effect of parenting styles (Hiramura et al, 2010).

\section{References}

Achenbach, Th. (2005). Manual of school age forms of the Achenbach Empirically based Assessment System (ASEBA), adaptation and standardization of Asghar Minaei. Tehran: Exceptional Children's Research Center.

Alizadeh, H., Hemmati Alamdarloo, Gh., Rezaei Dehnavi, S., \& Shojaei, S. (2012). Tehran: Arasbaran Publication, Third Edition.

American Psychiatric Association: Diagnostic and Statistical Manual of Mental Disorders, 5th Edition. (2013). Washington DC, American Association.

Asghari Nekah Seyyed, M. (2012). Why and how to prevent learning disabilities as a hidden disability (with a focus on reading disorder). Proceedings of the Second Conference on Disability Prevention. Exceptional Education Organization of Iran, First edition, Summer

Auerbach, J. G., Gross-Tsur, V., Manor, O., \& Shalev, R. S. (2008). Emotional and behavioral characteristics over a six year period in youths with persistent and non-persistent dyscalculia. Journal of Learning Disorders, 41, 263-273. https://doi.org/10.1177/0022219408315637

Behrad, B. (2005). Meta-analysis of the prevalence of learning disabilities in elementary school students in Iran. Research in the field of exceptional children. 5(4), (18), 417-437.

Costello, E. J., Erkanli, A., \& Angold, A. (2005b). The developmental epidemiology of child or adolescent depression? Journal of Child Psychology and Psychiatry, 47,1263-1271.

Crastnopol.M. (2009). Coming to Terms With Invisible Disability-Beyond Empathic Resonance: Commentary on Paper by Lauren Levine. Psychoanalytic Dialogues. 19, 474-479. https://doi.org/10.1080/10481880903088617

Diaz, Y. (2005). Association between parenting and child behavior problems among Latino mothers and children [dissertation]. Maryland: Univ Maryland.

Donatelli, J. A., Seidman, L. J., Goldstein, J. M., Tsuang, M. T., Buka, S. L. (2010). Children of parents with affective and non-effective psychoses: a longitudinal study of behavior problems. Am J Psychiatry, 167(11),1331-8. https://doi.org/10.1176/appi.ajp.2010.09020241

Dowker, A. (2005). Eerly identification and intervention for students With mathematics Difficulties. Journal of Learning Disorders, 38,328-331.

Freilich, R., Shechtman, Z. (2010). The contribution of art therapy to the social, emotional, and academic Adjustment of children with learning disorders. The Arts in Psychotherapy, 7(3), 97-105. https://doi.org/10.1016/j.aip.2010.02.003

Greman, Jin Ch. (2001). Emotional Disorders and Learning Disabilities. Translators: F Baezzat and M Rahat. (2007). Tehran: Payam-e Moallef Press, First Edition.

Ganji, M. (2013). Exceptional children psychology based on DSM-5. Tehran: Savalan Publishing.

Halahan, daniel P., Lloyd, J, Kauffman. J., Wies. Margaret, M., \& Elizabeth A. (2005). Learning Disturbances (Basics, Features and Effective Teaching), Translators:

Hemmati Alamdarloo, Gh, Hussein Khanzadeh, A. A., Arjmandi, M. S., Teimuri Asfichi, M. M., \& Taher, M. (2014). The role of maternal parenting styles in predicting behavioral problems of preschool children with mental retardation, Quarterly Journal of Exceptional Education, 14 (3) (125), 7-16.

Hiramura, H., Uji, M., Shikai, N., Chen, Z., Matsuoka, N., \& Kitamura, T. (2010). Understanding externalizing behavior from children's personality and parenting characteristics. Psychiatry Research, 175(1-2), 142-147. https://doi.org/10.1016/j.psychres.2005.07.041

Huver, R. O., Rose, M. E. C. M. E., \& Rutger, H. (2010). personality and parenting style in of adolescents Engles. Journal of Adolescence, 33, 395-402. https://doi.org/10.1016/j.adolescence.2009.07.012

Islamieh, M. M. (2008), The Prevalence of Behavioral Disorders in Elementary School Students in Tehran. Quarterly Journal of Exceptional Education, 8(1), 98-109.

Jakobsen, I. S., Horood, J., \& Fergussen, D. M. (2012). Childhood anxiety/withdrawal, adolescent parent-child attachment and later risk of depression and anxiety disorder. Journal of Child \& Family Studies, 21(2), 303-310.

https://doi.org/10.1007/s10826-011-9476-x 
Kafi, M., Zeinali, Sh, Khosro Javid, M., \& Miyah Nahri, F. (2013). Comparison of behavioral characteristics and social development of children with and without learning disabilities. Journal of Learning Disabilities, 2(4), 124-139.

Kessler, R. C., Avenevoil, S., \& Merikangas, K. R. (2005). Mood disorders in children and adolescents: An ep ideological perspective. Biological psychiatry, 49, 1002-1014. https://doi.org/10.1016/S0006-3223(01)01129-5

Khanjani, Z., \& Hadavandkhani, F. (2013). Internalizing and externalizing disorders of children and mother personality traits. Journal of Psychology, Spring 17(1), 33-52.

Kraskian, A. (2013). Bumerind parenting style questionnaire. Journal of Counseling School, Spring, 3(8), 40-41.

Lee, Ch. H. (2010). Personal and interpersonal correlates of bullying behaviors among Korean middle school students. Interpersonal Violence, 25(1), 152-176. https://doi.org/10.1177/0886260508329124

Lorber, M. F., \& Egeland, B. (2009). Infancy parenting and externalizing psychopathology from childhood through adulthood: Developmental trends. Developmental Psychology, 45( 4), 909-912. https://doi.org/10.1037/a0015675

McNamara, J. K. (2010). A Longitudinal Study of Risk-Taking Behavior in Adolescents with Learning Disorders. Learning Disorders Research \& Practice. 25(1), 11-24. https://doi.org/10.1111/j.1540-5826.2009.00297.x

Miller-lewis, L. R., Baghurst, P. A., Sawyer, M. G., Prior, M. R., Clark, J. J., Arney, F. M., \& Carbone, J. A. (2006). Early childhood externalizing behavior problems: child, parenting, and family-related predictors over time. Journal of abnormal child psychology, 34, 891-906. https://doi.org/10.1007/s10802-006-9071-6

Moradi, H., \& Rezaei, J. (2013). Childhood behavioral and emotional disorders (nature, evaluation and treatment). Vanya Publishing, First edition

Oliver, P. H., Guerin, D. W., \& Coffman, J. K. (2009). Big five parental personality traits, parenting behaviors, and adolescent behavior problems. Journal of Personality and Individual Differences, 47, 631-636. https://doi.org/10.1016/j.paid.2009.05.026

Paul, B. M., \& Fine, E. M. (2014). Learning Disability: Overview. Encyclopedia of the Neurological Sciences (Second Edition), 855-858. https://doi.org/10.1016/B978-0-12-385157-4.00435-8

Pandina, G. J., Bilder, R. H., Harvey, P. D., Keefe, S. E., Aman, M. G., \& Gharabawi, G. (2007). Risperidone and cognitive function in children with disruptive behavior disorder. Biological psychiatry. Neuroscience and BioBehavioral Review, 14, 253-262.

Pennington, B. F. (2009). Diagnosing learning disorders: A neuropsychological framework. New York: Guilford Press.

Rinaldi, C. M, \& Howe, N. (2012). Mothers' and fathers' parenting styles and associations with toddlers' externalizing, internalizing, and adaptive behaviors. Early Childhood Research Quarterly, 27(2), 266-273.

https://doi.org/10.1016/j.ecresq.2011.08.001

Sharma, G. (2004). A comparative study of the personality characteristics of primary school: Students with learning disorders and their non-learning disabled peers. Learning Disability Quarterly, 27, 127-140.

Sheikhi, A., Shafiepoor, S. Z.; Mirzaei, M., \&Kazemnejad Laili, E. (2015). Parenting styles and their relationship with children's behavioral problems. Nursing and Midwifery Journal of Comprehensive Nursing. 25(67), 49-56.

Sideridis, G. D. (2007). International approaches to learning disorders: More alike or more different. Learning Disorders Research \& Practice, 22, 210-215. https://doi.org/10.1111/j.1540-5826.2007.00249.x

Wang, T., \& Huang, H. (2012). The Performance on a Computerized Attention Assessment System between Children with and without Learning Disorders. Procedia - Social and Behavioral Sciences, 64, $202-208$. https://doi.org/10.1016/j.sbspro.2012.11.024

\section{Copyrights}

Copyright for this article is retained by the author(s), with first publication rights granted to the journal.

This is an open-access article distributed under the terms and conditions of the Creative Commons Attribution license (http://creativecommons.org/licenses/by/4.0/). 